\title{
Evidence for a change in neurotransmitter affecting oesophageal motility in Parkinson's disease
}

\author{
M. G. B R A M B L E, J C C N L I F F E, A N D A . W . D E L L I P I A N I \\ From the Gastrointestinal Unit, North Tees General Hospital, Stockton on Tees, and Department of \\ Neurology, Middlesbrough General Hospital, Cleveland
}

SUM MARY In a study of oesophageal motility in 20 patients with Parkinson's disease, intravenous atropine produced marked disruption of co-ordination in response to swallows, when compared with control subjects. This suggests that cholinergic rather than dopaminergic mechanisms are more important in the control of swallowing in patients with Parkinsonism. No conclusive evidence of peripheral dopamine depletion or autonomic neuropathy was found, although minor changes suggestive of the former were found in severely affected patients.

There are several reports of disordered oesophageal function in patients with Parkinson's disease. Segmental spasm has been noted radiologically (Penner and Druckermann, 1942; Eadie and Tyrer, 1965a) as has oesophageal dilatation (Gibberd et al., 1974) and gastro-oesophageal reflux (Eadie and Tyrer, 1965a). Only a few patients have been studied using manometric techniques, an increased incidence of non-peristaltic swallows being observed (Fischer et al., 1965). As dysphagia is common in Parkinson's disease (Eadie and Tyrer, 1965b) more detailed investigations into oesophageal motility were undertaken. Vagal function was also assessed.

\section{Methods}

Twenty unselected patients with idiopathic Parkinson's disease and 20 control subjects, matched for age and sex, gave informed consent before entering the study. Mean age was 66.5 years (range $48-85$ years). Anti-Parkinsonism therapy was stopped for 48 hours and disease severity assessed in terms of bradykinesia, rigidity, tremor, locomotion, and speech. Three patients had mild disease, seven moderate, eight severe, and two very severe. Eight patients had experienced dysphagia within the last six months, half of whom were troubled more than once a month. Five patients located their difficulty

Address for reprint requests: Dr M. G. Bramble, Gastroenterology Unit, Department of Medicine, Royal Victoria Infirmary, Newcastle upon Tyne, NE1 4LP.

Accepted 21 February 1978 to the pharynx, the remainder incriminating the lower oesophagus.

Oesophageal pressures were measured using a triple lumen tube with three distal orifices $50 \mathrm{~mm}$ apart and perfused at a constant rate of $0.6 \mathrm{ml} /$ min. Statham transducers and a Devices four channel recorder converted the pressures to graphic form. The lower oesophageal sphincter pressure (LOSP), peristaltic response to swallowing water (10 $\mathrm{ml}$, wet swallow), and swallowing without water (dry swallow) were recorded over a 25 minute period. Seventeen patients with Parkinson's disease were given a subcutaneous injection of $2.5 \mathrm{mg}$ bethanechol and 15 patients $0.6 \mathrm{mg}$ atropine intravenously, the responses being recorded for a further 25 minutes. The results were compared with age-matched controls who also received the same drugs.

Vagal function was assessed by recording the resting heart rate and beat to beat variation on deep breathing, from an ECG recording. Many patients with Parkinson's disease were unable to carry out a Valsalva manoeuvre because of bradykinesia and this test of vagal function could not be used.

\section{Results}

LOWER OESOPHAGEAL SPHINCTER PRESSURE The mean LOSP was similar in those patients with severe or very severe Parkinson's disease $(19.0 \pm$ $3.6 \mathrm{mmHg}$, mean $\pm \mathrm{SEM}$ ) when compared with those with mild to moderate disease $(13.8 \pm 2.4$ $\mathrm{mmHg})$ and control subjects $(13.4 \pm 1.6 \mathrm{mmHg}$ 
$P>0.1$. The mean increase in LOSP after bethanechol was less marked in patients with severe Parkinson's disease $(12.0 \pm 3.5 \mathrm{mmHg})$, compared with mild or moderate cases $(22.0 \pm 5.3 \mathrm{mmHg})$, but this difference was not significant. Atropine universally depressed the LOSP in all patients.

No significant differences emerged between the two groups with respect to amplitude, duration, and peristaltic rate of pressure waves, initiated by either a wet or dry swallow.

\section{CO-ORDINATION}

In the Parkinsonism group, $17.6 \%$ of 429 swallows failed to initiate peristalsis (non-peristaltic) compared to $15.8 \%$ of 385 swallows in the control group. There was no correlation between age, disease severity, or symptomatology and the number of non-peristaltic swallows. The effects of bethanechol and atropine on peristalsis are shown in the Table. The response to bethanechol was variable and did not show any significant differences between the two groups. Atropine, however, produced a significant increase in the number of non-peristaltic swallows in the Parkinsonism group compared with control subjects $(P<0.05)$. Patients with dysphagia were slightly more sensitive to atropine with an increase in non-peristaltic swallows of $65.7 \pm 6.7 \%$ (mean difference \pm SE difference) compared to $47.5 \pm 7.8 \%$ in those without dysphagia $(\mathrm{P}>0.05)$.

Table Mean difference \pm standard error of difference of percentage increase in non-peristaltic swallows after bethanechol and atropine.

\begin{tabular}{|c|c|c|c|c|}
\hline Group & $\begin{array}{l}\text { Mean } \\
\text { difference } \\
\text { after } \\
\text { bethanechol } \\
\pm S E \\
\text { difference }\end{array}$ & $\boldsymbol{P}$ & $\begin{array}{l}\text { Mean } \\
\text { difference } \\
\text { after } \\
\text { atropine } \\
\pm S E \\
\text { difference }\end{array}$ & $P$ \\
\hline $\begin{array}{l}\text { Parkinsonism } \\
\text { Controls } \\
\text { Difference } \\
\text { between groups }\end{array}$ & $\begin{array}{r}15.0 \pm 5.33 \\
3.7 \pm 6.43 \\
\\
11.31 \pm 8.53\end{array}$ & $\begin{array}{l}<0.02 \\
\text { ns } \\
\text { ns }\end{array}$ & $\begin{array}{l}52.4 \pm 6.21 \\
30.7 \pm 6.89 \\
21.65 \pm 9.28\end{array}$ & $\begin{array}{l}<0.001 \\
<0.001 \\
<0.05\end{array}$ \\
\hline
\end{tabular}

EFFECT OF PREVIOUS TREATMENT

Bias arising from severely affected patients on more intensive therapy was avoided by examining only those with mild to moderate Parkinsonism. The response to atropine was similar in those new patients not yet on therapy and those already on anticholinergics. The increase in non-peristaltic swallows was $56.9 \pm 13.6 \%$ in previously untreated patients and $62.2 \pm 12.4 \%$ in those after withdrawal of treatment. This difference was not significant.
VAGAL FUNCTION

Mild or moderately affected patients had significantly better vagal function in terms of resting $R-R$ interval $(P<0.05)$ and beat to beat variation (expressed as a percentage change in $R-R$ interval) $(P<0.01)$ than severely affected patients (Figure). However, the mean age of severely affected patients was 70.6 years compared to only 61.5 years in mild to moderate cases. As vagal function deteriorated with increasing age in both control subjects $(r=-0.468 \quad \mathrm{P}<0.05)$ and Parkinsonism patients $(r=-0.58 \quad \mathrm{P}<0.01)$, the results do not indicate a disease-specific disturbance. Vagal function was similarly impaired in age-matched control subjects.

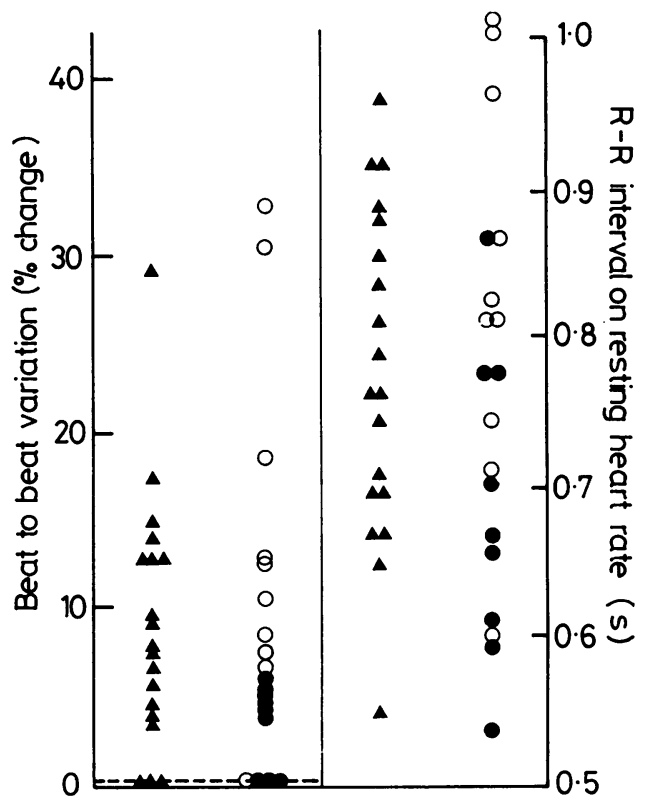

Figure Correlation between autonomic neuropathy, assessed by average resting $R-R$ interval and beat to beat variation of the same after deep breathing, and disease severity ( $O$ mild to moderate and $\bullet$ severe to very severe Parkinson's disease, control subjects $\Delta$ )

\section{Discussion}

Co-ordinated motor activity, vagal function, and the peripheral role of dopamine have been studied. Peristalsis in response to swallowing is controlled by the brainstem nuclei and reticular formation (Jean, 1972; Roman and Tieffenbach, 1972; Sumi, 1972). Local distension initiating peristalsis (Christensen and Lund, 1969) was not studied. The significant disruption of peristalsis in Parkinsonism patients after atropine was unexpected as other 
features such as tremor improved. In contrast, bethanechol worsened tremor and rigidity without affecting peristalsis significantly compared with control subjects. Improvement on anticholinergics and deterioration after cholinomimetics is well known (Duvoisin, 1967) and implies that either increased acetylcholine production or increased sensitivity is responsible for many symptoms of Parkinsonism.

The dorsal vagal nucleus, however, appears to maintain normal function since no abnormalities are detected during the first 25 minutes. The dramatic effect of atropine provides indirect evidence of a change of neurotransmitter. Thus cholinergic neurones may be replacing the functions of degenerating dopaminergic neurones quite effectively (Spehlman and Stahl, 1976). Overcompensation may be deleterious and produce dysphagia, as this symptom was associated with the highest incidence of disruption in peristalsis after atropine. Evidence already exists that the dorsal vagal nucleus is morphologically abnormal in Parkinson's disease (Eadie, 1963), and Fischer et al. (1965) noted increased motor dysfunction in a small number of patients on anti-cholinergics in the only other manometric study.

Autonomic dysfunction from a central abnormality has been observed in the presence of both normal and abnormal Valsalva responses (Appenzeller and Goss, 1971; Gross et al., 1972). Allowing for age, it seems unlikely that a vagal neuropathy exists in Parkinson's disease, and the present study, using two simple parameters, shows no difference between Parkinsonism patients and control subjects.

Circular oesophageal smooth muscle is controlled principally by cholinergic mechanisms although adrenergic (Christensen, 1975) and dopaminergic (Rattan and Goyal, 1976) receptors exist. In man, dopamine increases the amplitude of contractions in the body of the oesophagus while reducing LOSP (Mukhopadhyay and Weisbrodt, 1977). Patients severely affected with Parkinsonism tended to have a slightly higher LOSP and reduced response to bethanechol consistent with peripheral dopamine depletion, as the LOSP is not under vagal control (Rattan and Goyal, 1974). However, the differences were not significant and no conclusions can be drawn from this limited evidence.

Finally, how does the present study relate to previous cineradiological findings? Comparison is difficult although manometry is able to examine peristalsis and measure pressures more effectively. Using this technique, no oesophageal spasm was detected in nearly nine hours of resting motor activity and over 400 swallows. Eadie and Tyrer (1965a) thought that they were possibly underestimating spasm as patients were investigated while on anticholinergics. It is possible, however, that unusually vigorous non-peristaltic contractions were the result of anticholinergics exerting a central effect.

In conclusion, increased sensitivity to atropine in patients with Parkinsonism provides indirect evidence of increased cholinergic neurotransmission in brainstem nuclei. We suggest that such a change in neurotransmitter, if excessive, could account for the intermittent dysphagia first noted by James Parkinson 150 years ago.

\section{References}

Appenzeller, O., and Goss, J. E. (1971). Autonomic deficits in Parkinson's syndrome. Archives of Neurology (Chicago), 24, 50-57.

Christensen, J. (1975). Pharmacology of the esophageal motor function. Annual Review of Pharmacology, 15, 243-257.

Christensen, J., and Lund, G. F. (1969). Esophageal responses to distension and electrical stimulation. Journal of Clinical Investigation, 48, 408-419.

Duvoisin, R. C. (1967). Cholinergic-anticholinergic antagonism in Parkinsonism. Archives of Neurology (Chicago), 17, 124-136.

Eadie, M. J. (1963). The pathology of certain medullary nuclei in Parkinsonism. Brain, 86, 781-790.

Eadie, M. J., and Tyrer, J. H. (1965a). Radiological abnormalities at the upper part of the alimentary tract in Parkinsonism. Australian Annals of Medicine, 14, 23-26.

Eadie, M. J., and Tyrer, J. H. (1965b). Alimentary disorder in Parkinsonism. Australian Annals of Medicine, 14, 13-22.

Fischer, R. A., Ellison, G. W., Thayer, W. R., Spiro, H. M., and Glaser, G. H. (1965). Esophageal motility in neuromuscular disorders. Annals of Internal Medicine, 63, 230-247.

Gibberd, F. B., Gleeson, J. A., Gossage, A. A. R., and Wilson, R. S. E. (1974). Oesophageal dilatation in Parkinson's disease. Journal of Neurology, Neurosurgery, and Psychiatry, 37, 938-940.

Gross, M., Bannister, R., and Godwin-Austin, R. (1972). Orthostatic hypotension in Parkinson's disease. Lancet, 1, 174-176.

Jean, A. (1972). Localisation et activité des neurones deglutiteurs bulbaires. Journal de Physiologie, 64, 227-268.

Mukhopadhyay, A. K., and Weisbrodt, N. (1977). Effect of dopamine on esophageal motor function. American Journal of Physiology, 232, E19-E24.

Penner, A., and Druckermann, L. J. (1942). Segmental spasms of the esophagus and their relation to Parkinsonism. American Journal of Digestive Diseases, 9, 282-287. 
Rattan, S., and Goyal, R. K. (1974). Neural control of the lower esophageal sphincter. Journal of Clinical Investigation, 54, 899-906.

Rattan, S., and Goyal, R. K. (1976). Effect of dopamine on the esophageal smooth muscle in vivo. Evidence for excitatory and inhibitory dopamine receptors. Gastroenterology, 70, 377-381.

Roman, C., and Tieffenbach, L. (1972). Enregistrement de l'activité unitaire des fibres motrices vagales destinées à l'oesophage du Babouin. Journal de Physiologie, 64, 479-506.

Spehlman, R., and Stahl, S. M. (1976). Dopamine acetyl choline imbalance in Parkinson's disease. Lancet, 1, 724-726.

Sumi, T. (1972). Role of pontine reticular formation in the neural origination of deglutination. Japanese Journal of Physiology, 22, 295-314. 